\title{
De la teoría a la «especulación». La noción de evidencia en Duns Escoto.
}

\author{
From Theory to «Speculation». \\ The Concept of Evidence in Duns Scotus.
}

\author{
RAFAEL CORAZÓN GONZÁLEZ. \\ Grupo de Investigación sobre el idealismo alemán de la Universidad de Málaga
}

Recibido: 11/IV/2014 Aprobado definitivamente: 11/X/2014

RESUMEN

La distinción entre conocimiento intuitivo y abstractivo, extendida por Duns Escoto, y la consiguiente distinción entre conceptos distintos y confusos, implica una nueva gnoseología en la que la inteligencia asiste pasivamente, como un espejo, a la representación de las esencias, que se manifiestan al margen de su existencia.

PALABRAS CLAVE

CERTEZA-EVIDENCIA-INTUICIÓN-CONOCIMIENTO ABSTRACTIVOIDEAS CLARAS Y DISTINTAS.

\section{ABSTRACT}

The distinction between intuitive and abstractive knowledge, spread by Duns Scotus, and the consequent distinction between different and confused concepts, it involves a new gnoseology in which intelligence assists passively, like a mirror, to the presentation of essences, manifested apart from its existence.

KEY WORDS

CERTAINTY-EVIDENCE-INTUITION-ABSTRACTIONCLEAR AND DISTINCT IDEAS.

(C) Contrastes. Revista Internacional de Filosofia, vol. XX No 2 (2015), pp. 251-267. ISSN: 1136-4076 Licenciatura de Filosofía, Universidad de Málaga, Facultad de Filosofía y Letras Campus de Teatinos, E-29071 Málaga (España) 


\section{EL CRITERIO DE CERTEZA.}

ES FRECUENTE ENCONTRAR en los manuales, como doctrina asumida pacíficamente dentro de la tradición tomista, la siguiente relación entre verdad, evidencia y certeza: la ciencia es un conocimiento cierto; el criterio de certeza es la evidencia objetiva, la cual nos asegura de estar en la verdad. Algunos ejemplos lo ilustrarán.

«El término certeza no expresa tanto el asentimiento que denominamos cierto cuanto la firmeza que presenta a la conciencia ese asentimiento; por lo tanto, en el complejo asentimiento-firme, el término certeza expresa in recto la firmeza, in obliquo el asentimiento; impropiamente, y por una cierta metonimia, indica el objeto acerca del cual se da un juicio cierto [...]. La certeza es, pues, una cualidad del acto mental, así como la evidencia es una cualidad del objeto o cosa. Directamente, ni hay objetos ciertos ni conocimientos evidentes; sólo indirectamente se da esa trasposición gnoseológica». ${ }^{1}$

La relación entre estas situaciones de la mente es la que sigue: «parece claro, por cierto instinto gnoseológico, que la evidencia es tanto la última razón de toda verdad como la última causa de toda certeza, y que es por la evidencia por lo que distinguimos inequívocamente la verdad». ${ }^{2}$

En definitiva, «la evidencia se nos presenta como una noción estrictamente indefinible; sólo admite una descripción análoga, incluida en el mismo término: evidentia, de videre. De ahí que aun el mismo entendimiento decimos que ve, hablamos de visión del entendimiento, cuando se le presenta la verdad clara». ${ }^{3}$ Evidente es, pues, lo que se ve, ante la vista o, por analogía, ante la mente; por eso santo Tomás apunta: illa videre dicuntur quae per se ipsa movent intellectum nostrum vel sensum ad sui cognitionem. ${ }^{4}$ Aunque no pueda definirse, puede describirse del siguiente modo: «la actual y clara inteligibilidad del objeto o la actual y clara manifestación del objeto». ${ }^{5}$

La evidencia nos asegura de estar en la verdad. Sin embargo, en los sentidos externos -y en concreto la vista, de donde se toma el término-, la especie expresa no es retenida sino que sólo permanece mientras el sentido

1 Alejandro, J. M. de, 1969, 179.

2 Ibid. 149.

3 Ibid. 149-150.

4 Santo Tomás de Aquino, 1959, II-II, q. 1, a. 4: «se dice que hay visión cuando la cosa mueve por sí misma a nuestro entendimiento o nuestro sentido a su conocimiento».

5 Alejandro, J. M. de, op. cit. 150. 
conoce, ${ }^{6}$ y ello porque requiere de un estímulo físico - especie impresa ${ }^{7}$. . Por eso, aunque «sólo con relación a un acto de conocer la piedra se puede decir conocida en acto», ${ }^{8}$ santo Tomás no tiene inconveniente en afirmar que «las realidades sensibles están en acto fuera del alma y, por tanto, no hay necesidad de un sentido agente». ${ }^{9}$ En cambio, la inteligencia no puede ser impresionada por lo material -incorporeum non potest inmutari a corporeo ${ }^{10}$-. Se requiere, por tanto, hacer inteligible en acto lo que lo es sólo en potencia, un «acto de los inteligibles en acto» -el intelecto agente.

Teniendo en cuenta esta diferencia entre la sensibilidad externa y la inteligencia, ¿puede decirse que esta última «ve», o sea, intuye? ¿Puede establecerse un paralelismo entre la inmutación física y la luz del intelecto agente?

Aquí los autores se dividen. Para unos la evidencia es la presencia de la «cosa» a la mente; para otros, en cambio, lo presente es el «objeto». Y algunos son ambiguos, pues unas veces toman el término objeto como sinónimo de cosa y otras no. Por eso, decir que «la realidad, la cosa, el objeto, es radicalmente inteligible» ${ }^{11}$ no aclara la cuestión.

Según esto, la evidencia es una propiedad del objeto. Pero no todos los autores que siguen la gnoseología clásica y, en concreto, tomista, son del mismo parecer, pues distinguir objetos evidentes de los no evidentes requeriría un nuevo criterio.

El problema de la evidencia, entendida como claridad, se complica al distinguir entre la claridad de lo real y la del entendimiento. Porque, aunque «la luminosidad o claridad [...] pertenece radicalmente al mismo ser [...]. La verdad ontológica es la radical luminosidad de todo ente, justo en tanto que ente. No puede haber otro déficit de verdad ontológica que el que estriba en la limitación o finitud de la entidad. Todo ente finito es deficientemente luminoso por la misma limitación de la entidad que posee. Pero también todo cuanto posee una cierta entidad, por precaria que fuere, es, en la medida justa de ella, algo que puede llegar a ser objeto de una exacta y clara intelección», ${ }^{12}$ en la

6 «La vista es estrictamente presencial; no puede aludir a lo visto antes. Aludir a lo visto antes es recordar, pero no es ver: lo visto antes, no se ve; no se debe decir: se ve que antes se ha visto, sino: se recuerda que se ha visto». Polo, L., 1987, 318.

7 «La especie impresa se corresponde con el proceso nervioso... La especie impresa no es el proceso físico externo, sino su influjo en el órgano: es el órgano impresionado. Como el órgano está vivo asume el estímulo según su propia índole, es decir, según la forma que lo constituye en facultad.» Polo, L., op. cit. 349.

8 Ibid. 49.

9 Santo Tomás De Aquino, 1959, I, q. 79, a. 3 ad 1.

$10 \mathrm{Ibid}$, I, q. 84, a. 6: «lo incorpóreo no puede ser impresionado por lo corpóreo».

11 Alejandro, J. M. de, op.cit. 150.

12 Millán Puelles, A., 1984, 272. 
práctica ocurre lo contrario: lo más perfecto es menos conocido por nosotros porque, como decía Aristóteles, como el búho, quedamos deslumbrados por tanta luz. Por eso, la evidencia, por muy ontológica que sea, tiene un componente subjetivo, ya que lo evidente lo es para el entendimiento, e incluso, a veces, no para todo entendimiento, sino sólo para algunos.

Como muestra de la diversidad de opiniones vamos a examinar brevemente otra posición: «La evidencia es la claridad con la que un objeto aparece a una facultad de conocimiento, la manifestación o, como actualmente se dice, la revelación del ser»; ${ }^{13}$ pero tiene buen cuidado en aclarar que «objeto» no es la realidad, sino la realidad en cuanto conocida. Por eso, puede decirse que «el criterio [de certeza] no puede ser ni puramente subjetivo ni puramente exterior, debe ser ambas cosas a la vez, y es lo que ocurre en la evidencia en la que el objeto y el sujeto están unidos en la claridad». ${ }^{14}$

Como conclusión sirva el siguiente texto: «la definición clásica en la escuela es la siguiente: evidentia est claritas qua obiectum manifestatur intellectui et assensum rapit. Las palabras intellectus y rapere requieren algún comentario: porque no es necesario que el objeto sea una esencia abstracta directamente inteligible. Basta que un objeto aparezca a una facultad cualquiera, sentido, conciencia, lo mismo que a la inteligencia, o digamos que aparezca al hombre de tal modo que su presencia (intencional) ocasione un juicio. Por otra parte, no es necesario que el objeto determine el juicio por el juego de algún mecanismo psicológico. Basta que lo exija o lo requiera, desde el punto de vista crítico, es decir, que la inteligencia no pueda negar su asentimiento sin negar su apetito natural de verdad». ${ }^{15}$

Estas cuestiones no son puramente académicas, sino que tienen importancia a la hora de conocer la verdad porque ¿de qué sirve estar en la verdad si no se sabe que se posee? ${ }^{16}$

Santo Tomás dice al respecto: «la verdad sigue a la operación del entendimiento en tanto que el juicio de éste se refiere a la cosa tal como ella es; pero la verdad es conocida por el entendimiento en tanto que éste reflexiona sobre su propio acto [...]. Luego el entendimiento conoce la verdad en cuanto que reflexiona sobre sí mismo». ${ }^{17}$ Reflexionar sobre sí mismo no es, en modo alguno, el mismo acto que conoce la realidad. Más explícito, por eso, es quizás el siguiente texto: in hac sola secunda operatione intellectus est veritas et falsi-

13 Verneaux, R., 1971, $2^{\mathrm{a}}$ ed., 146.

14 Ibid, 157.

$15 \mathrm{Ibid}$., 150. «La evidencia es la claridad con la que el objeto se manifiesta al intelecto y le impulsa a asentir».

16 Cfr. Santo Tomás de Aquino, 1999, lect. 4; 1967, I, 59; 1959, I, q. 16, a. 2; 1999 (2), q. 1 , a. 3 .

17 Santo Tomás de Aquino, 1999 (2), q. 1, a. 9. 
tas, secundum quam non solum intellectus habet similitudinem rei intellectae, sed etiam super ipsam similitudinem reflectitur, cognoscendo et diiudicando ipsam. ${ }^{18}$ La reflexión versa sobre ipsam similitudinem, conocida previamente, que además se da en la segunda operación, o sea, en el juicio.

\section{El CONOCIMIENTO INTUITIVO.}

La clave para resolver estas dificultades está en la admisión, o no, de la intuición intelectual. Pero, como sucede con frecuencia, los textos clásicos no son unánimes, y requieren de un estudio que, más allá de una mera interpretación, llegue a la raíz de los malentendidos.

Santo Tomás afirma numerosas veces que la primera operación de la inteligencia es la abstracción a partir de los sentidos, y que el objeto propio del entendimiento es la esencia de las realidades sensibles. O sea, santo Tomás niega la existencia de intuición intelectual en el hombre, si por tal se entiende la pasividad del conocimiento.

Sin embargo, hay textos que parecen contradecir esta doctrina. O quizás la dificultad esté en saber qué se entiende por intuición. "Aunque sea casi tan clásico oponer intuición y abstracción como oponer intuición y discurso, no puede admitirse sin reservas la primera alternativa. La abstracción, tomada estrictamente como paso del fantasma al concepto, es sin duda un discurso. Pero va a parar a una intuición. Por el concepto, en efecto, gracias a él, se hace presente una esencia a la inteligencia, de modo que el acto de ésta es simple contemplación, visión, intuición. Al decir esto no hacemos más que traducir expresiones familiares a santo Tomás: intelligere dicit nihil aliud quam simplicem intuitum intellectus in id quod sibi est praesens intelligibili (I Sent. III, 4, 5). Illa praesto esse dicuntur intellectui quae capacitatem eius non excedunt, ut intuitio intellectus in eis figatur (Ver. 14, 9; cf. id., 1 ad 7). Dicitur intellectus ex eo quod intus legit, intuendo essentiam rei (Ethic. VI, 5, n. 1179). Intellectus cognoscit simplici intuitu, ratio vero discurrendo de uno ad aliud (S. Th., I, 59, 1 ad 1). Operatio intellectus quae est visio... (S. Th., I-II, 4, 2; cf. S. Th., I, 12, 11 ad 4; C.G., III, 53). Illa dicuntur videri quae per seipsa movent intellectum nostrum vel sensum ad sui cognitionem $\left(S\right.$. Th., II-II, 1, 4)». ${ }^{19}$

18 Santo Tomás de Aquino, 1999, lect. 4, n. 1236: «solo en esta segunda operación del intelecto se da la verdad y la falsedad, porque en ella el intelecto no sólo tiene la semejanza de la cosa entendida, sino que también reflexiona sobre dicha semejanza, conociendo y juzgando sobre ella».

19 Verneaux, R., 1971, 112. «Entender algo no es otra cosa que la simple visión del intelecto sobre el inteligible que le es presente»; «Se dice que el intelecto conoce inmediatamente aquello que no excede su capacidad, en lo que queda fija su mirada»; "se dice intelecto porque lee dentro, intuyendo la esencia de la cosa»; El intelecto conoce por simple mirada; la razón, en 
La dificultad es menor si se tiene en cuenta que, en los textos citados por Verneaux, se habla de la simple aprehensión o del concepto como conocimiento «simple» o de lo incomplejo, es decir, de conocimiento no discursivo. En este sentido es como cabe comparar el conocimiento intuitivo, propio de los sentidos externos, y la simple aprehensión. La diferencia, sin embargo, no debe olvidarse: los sentidos intuyen en la medida en que la especie sensible es apta por sí misma para inmutar al sentido. El intelecto no puede intuir de este modo porque su objeto sólo es inteligible en potencia y, por tanto, debe ser actualizado. Santo Tomás jamás dejó de afirmar que intellectum est in inteligente per suam similitudinem. Et per hunc modum dicitur, quod intellectum in actu est intellectus in actu; in quantum similitudo rei intellectae est forma intellectus [...]. Unde non sequitur quod species intelligibilis abstracta sit id quod actu intelligitur, sed quod sit similitude eius. ${ }^{20}$

Y definitivamente expresa su pensamiento en los siguientes términos: «si el entendimiento agente fuese con respecto al entendimiento posible lo que es el objeto que actúa con respecto a la potencia sobre la que actúa -al modo de lo que para la vista es el objeto visible en acto-, se seguiría que todo lo entenderíamos al instante, al ser el entendimiento agente quien hace inteligibles todas las cosas. Mas de hecho no se comporta como objeto, sino como lo que pone en acto a los objetos, para lo cual se requiere, además de la presencia del entendimiento agente, la presencia de imágenes sensibles, juntamente con la buena disposición de las potencias sensitivas y su ejercicio en esta clase de operaciones, puesto que el conocimiento de una cosa conduce al conocimiento de otras, como por medio de los términos se conocen las proposiciones y por los primeros principios las conclusiones». ${ }^{21}$

Por tanto, la intuición intelectual es distinta de la sensible, pues el intelecto agente ha de iluminar la sensibilidad interna, pero luego la inteligencia ha de realizar el acto de entender. Si no fuera así, la inteligencia sería una potencia puramente pasiva.

cambio, discurriendo de un inteligible a otro»; «la operación del intelecto que es la visión...»; Se dice ver aquellas cosas que por sí mismas mueven a nuestro intelecto o a nuestro sentido a su conocimiento».

$20 \mathrm{Ibid}$., I, q. 85, a. 2 ad 1: «lo entendido está en quien entiende por medio de una representación, y por eso se dice que lo entendido en acto es el entendimiento en acto, en cuanto que la semejanza entendida es la forma del entendimiento [...]. Por eso, no se sigue de aquí que la especie inteligible abstracta sea lo que se entiende en acto, sino que es su imagen».

21 Ibid., I, q. 79, a. 4 ad 3. 


\section{LA INTUICIÓN Y EL CONOCIMIENTO ESPECULATIVO.}

El equívoco, en numerosos autores, que les lleva a afirmar que la evidencia requiere la presencia de lo real ante el intelecto, se debe seguramente a la distinción, asumida y extendida por Duns Escoto, entre conocimiento intuitivo y conocimiento abstractivo.

Esta distinción llevó a unas consecuencias que tendrán una importancia capital en la filosofía moderna. El conocimiento intuitivo es el que, con propiedad, puede llamarse «especulativo», en el sentido de que la mente es pasiva, como un espejo que refleja la realidad, hasta el punto de caracterizar el conocimiento abstractivo como aquel por el cual no es posible saber si lo conocido existe o no existe. ${ }^{22}$ Esta distinción implica necesariamente admitir que la intuición es el único modo de conocer la existencia, y que, por ello, requiere la presencia de la realidad conocida. ${ }^{23}$

Pero además de conocer la existencia, hace posible también la «intuición de esencia». Escoto -y otros muchos autores- afirma que sólo el conocimiento intuitivo permite saber si lo que existe, existe, y lo que no existe no existe, pero en realidad el asunto es algo más complejo, pues la diferencia fundamental entre el conocimiento intuitivo y el abstractivo implica algo más relevante. En concreto, «si por intuición se entiende el conocimiento inmediato, no discursivo, como el de un color, es decir, de algo cuyo aparecer no exige mediación (una inducción o una deducción o, en general, un proceso comparativo), puede decirse que, cuando vemos, cuando tocamos, o cuando concebimos, intuimos. Este sentido de la intuición es correcto. Pero si por intuición se entiende que la actividad y el protagonismo del conocimiento corre a cargo de lo conocido, hay que excluirlo: sin acto de conocer no se conoce nada y eso quiere decir que no hay nada conocido». ${ }^{24}$ Dicho de un modo más directo: «la forma más general de admitir la pasividad cognoscitiva es el sentido que tiene con fre-

22 «Puede haber un conocimiento del objeto que abstrae de su existencia actual y puede haber un conocimiento del objeto en cuanto existe y en cuanto está presente en su existencia actual». Duns Escoto, 1300, II, d. 3, q. 9, n. 6.

23 «Interesa destacar una diferencia importante entre ambos tipos de conocimiento, el intuitivo intelectual y el abstractivo. Los dos pueden tener un mismo objeto; por eso su diversidad no puede derivar del objeto [...]. La distinción específica entre ambos tipos de conocimiento se encuentra en su aspecto formativo, o sea, en las distintas razones formales que los motivan. Es el mismo objeto en su propia y actual existencia el que motiva por sí y objetivamente el conocimiento intuitivo, mientras que, en el saber abstracto, lo que motiva objetivamente el conocimiento es otra realidad, distinta del objeto real, en la cual se halla contenido el objeto en cuanto a su ser cognoscible, ya sea como causa virtual de su conocimiento, ya sea en forma de una semejanza representativa del objeto real». Saranyana, J. I., 1985, 265-266.

24 Polo, L., op. cit., I, 47-48. 
cuencia (no siempre) la noción de intuición. Incluso se dice que la forma más alta de conocimiento es el intuitivo [...]. Al usar con este sentido la palabra 'intuición' se quiere decir que conocer es sencillamente asistir a la presencia de lo conocido (justamente lo intuido). Lo intuido es lo que se da desde sí, de manera que conocer, intuir, no es ejercer ninguna operación, sino simplemente estar asistiendo [...]. El conocimiento es tan inmediato que sólo existe realmente lo intuido, que se impone y llega, digámoslo así, hasta el entresijo más íntimo de mi posibilidad de conocer; justamente por eso lo conozco, no porque con lo intuido se corresponda un acto mío». ${ }^{25}$ Intuir, por tanto, es, en este sentido, ser impresionado pasivamente, y, por consiguiente, estar «ante» la realidad.

Pero volvamos a Duns Escoto. «Tomás de Aquino había sostenido que al estar nuestro intelecto vinculado al cuerpo, le es imposible ejercer ningún acto de conocimiento intelectual sin recurrir al fantasma (cfr. STh., I, q. 84, a. 7). Duns Escoto sin duda coincide con esto, en lo que respecta a todo acto de conocimiento natural en nuestro estado presente [...]. Lo que Duns Escoto pone en duda es que esta situación de hecho sea una situación de derecho. En otras palabras, el hecho de que la quididad abstracta de lo sensible sea el único objeto naturalmente accesible al intelecto humano pro statu isto no autoriza a concluir que sea el objeto primero del intelecto». ${ }^{26}$

El estado de naturaleza íntegra no es el mismo en santo Tomás y en Escoto. Santo Tomás defiende que la visión de Dios de que gozan los bienaventurados se debe al lumen gloriae y escapa por completo a la capacidad natural del hombre. Escoto, en cambio, afirmando también que la bienaventuranza es un don gratuito, cree necesario dotar a la inteligencia humana de la capacidad de conocer intuitivamente, o sea, «de captar directamente una esencia inteligible como tal». ${ }^{27} \mathrm{Su}$ argumento es como sigue: «la teología enseña en efecto que el mismo intelecto, que sólo conoce actualmente por modo de abstracción a partir de lo sensible, conocerá naturalmente más tarde la quididad de la sustancia inmaterial. Esto resulta claramente de lo que enseña la fe en lo referente al modo de conocer del alma bienaventurada. Ahora bien, una facultad de conocer no podría, sin cambiar de naturaleza, aprehender algo que no esté contenido en su objeto primero. Por tanto, es teológicamente insostenible que la quididad de la cosa material sea el objeto primero del intelecto». ${ }^{28}$

25 Ibid., I, 33-34.

26 Gilson, E., 2007, 66. Para Escoto el objeto primero y propio no es la esencia sino el «ente común unívoco»: «Nada más particular que el ser puede ser el objeto primero de nuestro intelecto, sin el cual el ser considerado y en sí no sería de ninguna manera conocido por nosotros»: Duns Escoto, J., 1300, I, d. 3, q. 3, n. 3.

27 Gilson, E., 2007, 45.

28 Ibid., 67. 
El argumento escotista es teológico, pero tendrá consecuencias graves para la filosofía y para la antropología. Porque ahora resulta que el hombre, pro statu isto, conoce mucho menos de lo que podría y debería conocer si su naturaleza conservara su integridad. «Duns Escoto mantiene firmemente que el conocimiento abstractivo no es exigido por la naturaleza misma del intelecto humano, como si debiera ser de este modo ex natura potentiae, sino que, en realidad, nos ha sido impuesto de un modo que sólo puede ser provisorio. El intelecto humano está condenado al modo abstractivo de conocer, que es aquí el suyo, no por su naturaleza, sino propter statum aliquem, es decir [...], en razón de 'un cierto estado' [...]. En síntesis, es el teólogo y no el filósofo, quien conoce las condiciones de hecho según las cuales se elabora nuestra filosofía». ${ }^{29}$

Puede decirse, por tanto, que «si la metafísica tomista es la de un intelecto cuya naturaleza y cuyo funcionamiento no han sido alterados por el pecado original, la metafísica escotista es la de un intelecto cuyo funcionamiento ha sido profundamente alterado por el pecado original, pero cuya naturaleza primitiva, siempre intacta, se advierte en la manera según la cual, aun herido, él funciona». ${ }^{30}$

Por eso, y es otra consecuencia importante del estado actual del hombre, «la independencia del intelecto con respecto al cuerpo glorioso establece, sin discusión posible, que la colaboración de hecho que reina actualmente entre este intelecto y su cuerpo no está requerida por la naturaleza misma del intelecto» $;{ }^{31}$ de ahí que la intelección -el acto del intelecto pasivo-, sea, de entrada, una reacción ante la presencia de un inteligible, de suerte que «la inteligibilidad precede siempre a la intelección, pues ésta no es, propiamente hablando, la producción de lo inteligible por el intelecto agente, sino más bien... la modificación pasiva del intelecto posible por la especie inteligible que produce el intelecto agente». ${ }^{32}$

29 Ibid., 69 y 78. «Ha sido establecido por las leyes de la sabiduría divina que nuestro intelecto sólo conciba, en su estado presente, aquello cuyas especies brillan en el fantasma, y esto ocurre, ya sea en castigo por el pecado original, ya sea a causa de la solidaridad natural de las facultades del alma cuando operan, puesto que vemos a la facultad superior ocuparse de lo mismo que la facultad inferior, cuando la operación de una y de otra es perfecta. En realidad, las cosas se nos presentan de tal manera que cualquier universal que nuestro intelecto concibe, nuestra imaginación se lo representa actualmente en lo singular. En todo caso, esta solidaridad, que existe en realidad en nuestro estado presente, no tiene que ver con la naturaleza de nuestro intelecto, ni aun en tanto que se halla en un cuerpo, ya que, si así fuera, la misma solidaridad lo vincularía al cuerpo glorioso, lo cual es falso». Duns Escoto, J., 1300, I, d. 3, q. 3, a. 4, n. 24.

30 Gilson, E., 2007, 80.

31 Ibid., 72.

32 Ibid., 513. 
En su lucha contra el averroísmo latino, Escoto limita el alcance de la razón, en el presente estado, y, por tanto, de la metafísica. Si la ciencia trata sobre lo necesario y los decretos divinos en orden a la salvación son libres, entonces la razón no puede acceder a ellos de ningún modo. ¿Cómo limita Escoto la capacidad de conocer del hombre y por qué? «Duns Escoto ha tomado de Aristóteles y de sus intérpretes árabes el ideal de una ciencia necesaria, fundada enteramente en los principios evidentes y en demostraciones racionales. Pero es el primero que se sirve de este principio para restringir y limitar el dominio del conocimiento humano. Su alto concepto de la ciencia se une en él con el reconocimiento de los límites rigurosos de la ciencia humana. Lo que no es demostrable no es necesario, sino contingente, y por esto arbitrario o práctico. Puesto que el único dominio de lo contingente es la acción, lo que no es necesario es término o producto de la acción humana o divina, o bien regla de acción, esto es, fe [...]. Escoto considera imposible demostrar todos los atributos de Dios, y aun, como veremos, la inmortalidad del alma humana. Con esto la certeza de estas proposiciones se convierte en certeza práctica, esto es, fundada exclusivamente en su libre aceptación por parte del hombre. El ideal aristotélico de la ciencia demostrativa lleva aquí a rechazar definitivamente fuera del ámbito de la investigación filosófica fundamentos básicos de la religión católica. La escolástica se encamina a vaciar de todo contenido su problema central». ${ }^{33}$

Las consecuencias que se derivan de esta posición son muy serias. La principal, para lo que aquí interesa, es que ahora es posible alcanzar la intuición de una esencia real, a partir de aquello que ha sido sentido. Como el intelecto, por su misma naturaleza, no depende del conocimiento sensible, dicho conocimiento lo obtiene «produciendo» una especie impresa que, propiamente, no puede decirse que ha sido abstraída del fantasma o imagen sensible, ya que «el intelecto agente escotista no trabaja sobre el fantasma para abstraer de él lo que fuere; él no abstrae, ni extrae, ni transforma nada; él causa y produce lo inteligible en virtud del poder que le confiere su separación del cuerpo», ${ }^{34}$ aunque requiere de la imagen sensible en el presente estado, como causa parcial cuyo concurso es necesario.

Por eso, las esencias o formalidades pueden considerarse según tres posibles estados. En concreto, «el conocimiento comienza por conceptos confusos, cada uno de los cuales representan uno de los objetos de experiencia a los cuales damos nombre. Estos objetos son ellos mismos individuos, seres 'singulares', cuya especie sensible actúa sobre el oído, la vista y el tacto. Si su acción sobre el sentido es lo suficientemente fuerte, su species es reconocida inmediatamente

33 Abbagnano, N., 1994, 510-511.

34 Gilson, E., 2007, 511. 
por el intelecto. Se produce entonces en nosotros un concepto del individuo en cuestión, pues el singular nos es cognoscible; pero este concepto sigue siendo confuso, porque no conocemos el singular pro statu isto, bajo su razón propia de singular. Lo que en primer lugar se da en el orden de la adquisición del saber es, por lo tanto, el singular conocido de manera confusa». ${ }^{35}$

Pensar que las operaciones intelectuales no son actos que poseen el fin, es pensarlas como acciones transitivas o como pasiones. Y este es el caso de Escoto. ${ }^{36}$ Escoto reconoce cierta actividad al entendimiento cuando ha sido afectado por la especie impresa, o sea, de una manera reactiva; y esto le lleva a entender el conocimiento como «especulación», como una imagen de la realidad; pero una imagen -como la del espejo- irreal que, sin embargo, representa lo real, al margen de su existencia. Aunque «el objeto sólo es intuitivamente conocido en tanto que existente [...], no se debe olvidar, por otra parte [...] que el objeto de la ciencia sigue siendo para él la esencia: 'cum ratio in anima possit manere non manente existentia actuali obiecti, sequitur quod existentia non est per se ratio obiecti ut scibili est, quia ratio scientifica non potest manere eadem in anima, non manente illo eodem quod est per se ratio scibilis, ut scibilis est; sive autem scibile possit existere in re, sive non, saltem ratione eius, ut scibile est, potest manere eadem in anima, non manente existentia: abstrahit ergo scientia ab existentia, ita quod non includit eam in ratione scibilis' (Quaestiones Quodlibetales, q. 7, n. 9)».37 Además, la especie expresa tiene realidad propia, entidad, ya que «el intelecto agente no produce la 'representación'; él causa un 'ser representativo'. De este modo, 'la acción real del intelecto agente tiene como término una forma dotada de existencia real (formam aliquam realem in existentia)' (Opus Ox., I, d. 3, q. 6, n. 8; t. I, p. 405. Reportata Parisiensia, I, d. 3, q. 4, n. 4)». ${ }^{38}$ Con ello la inteligencia no puede salir de sí misma: ha perdido la intencionalidad. Por eso «la sospecha de que las formalidades de Escoto no son verdaderas ellas solas (en el débil sentido que la verdad conserva en el caso) está a la vuelta de la esquina, porque un speculum, en todo caso, es una pantalla; pero no es una energía: no asimila, no es una consideración interna:

35 Ibid., 82.

36 Es significativo que las «procesiones» de las Personas divinas reciban en Escoto el nombre de «producciones».

37 Gilson, E., op. cit., 548-549, nt. 73. «Como la razón de objeto puede permanecer en el alma sin que permanezca la existencia actual del objeto, de ahí se sigue que la existencia no pertenece, por sí, a la razón (noción) de objeto en cuanto cognoscible; porque la ciencia no puede permanecer la misma en el alma si no permanece aquello que es por sí cognoscible en cuanto cognoscible; lo cognoscible puede existir en la cosa o no, pero al menos su razón (noción), en cuanto cognoscible, puede permanecer en el alma aunque no permanezca la existencia: la ciencia abstrae, por tanto, la existencia, de modo que no la incluye en la razón de lo cognoscible.»

38 Ibid., 509. 
Escoto ha desvitalizado la inteligencia; las formalidades son capaces de dar razón de sí tan sólo en cuanto posibles. Es imparable la sospecha acerca del valor cognoscitivo de nuestro pensamiento en cuanto precisivamente objetivo, que es otra manera de decir que es especulativo». ${ }^{39}$

El conocimiento es, de entrada, confuso. Sin embargo, «para que un concepto sea conocido distintamente, es preciso que sea conocido todo lo incluido en la noción de su esencia». ${ }^{40}$ Por eso, para Escoto el conocimiento distinto del ser es su conocimiento como concepto unívoco, puesto que «puede ser concebido aparte de cualquier otro y sin ninguna determinación ulterior, pero ningún otro puede ser concebido sin él. En otras palabras, el ser es el objeto de un conocimiento distinto absolutamente simple y es el único concepto de este tipo; por lo tanto, el ser es el primer concepto distintamente concebible y distintamente concebido». ${ }^{41}$

Escoto es categórico en este punto, del que depende toda su filosofía: «No pudiendo haber nada más común que el ente, y no pudiendo, a su vez, ser el ente-común-unívoco predicado de la quididad de todos los inteligibles, ya que no es predicable de las diferencias últimas ni de sus pasiones, se sigue que la nada es el primer objeto de nuestro entendimiento, pues es por sí misma común a la quididad de todo inteligible; no obstante, digo que el primer objeto de nuestro entendimiento es el ente, ya que en él concurren estas dos primacías: la comunidad y la virtualidad. Todo inteligible, o incluye esencialmente la razón de ente, o está contenido virtualmente en lo que incluye esencialmente la razón de ente». ${ }^{42}$ Este texto es clave y merece que examinemos las consecuencias que de él se derivan.

¿Quiere decirse, entonces, que no podemos saber qué esencias son reales y cuáles son sólo abstractas? No. La doctrina de Escoto, por extraña que pueda parecer, tiene su propia lógica. «Para que Duns Escoto mismo haya concebido el ens commune como real, y no como lógico, es preciso claramente que haya admitido una comunidad distinta de la del orden lógico, o, en otras palabras, que lo 'común' pueda ser al mismo tiempo para él real. Por ello es posible distinguir, en su doctrina, entre la generalidad propiamente dicha del concepto (universalidad) y la comunidad real de la esencia. Todo lo que es metafísicamente «común» es universalmente predicable, pero no todo lo universalmente

39 Polo, L., 1993, 55. «La teoría del conocimiento escotista comienza la andadura moderna de las alternativas al realismo gnoseológico (racionalismo, idealismo, etc.). Para Escoto el objeto es previo, anterior al acto, el objeto es en-sí, porque es la realidad-objeto; el objeto no es mero objeto, no es mero 'estar-ante'. En consecuencia, el objeto causa el acto...» Miralbelli, I., 1994, 272.

40 Gilson, E., 2007, 83.

41 Ibid., 83.

42 Duns Escoto, 1300, I, d. 3, q. 3, n. 137. 
predicable es metafísica y realmente común. Lo metafísicamente común es precisamente un ser en la razón, como el universal lógico, pero no es un 'ser de razón', pues la metafísica no lo considera según este aspecto, sino como un objeto real. Lo metafísicamente común es aquello que hay de actualmente común en la realidad. Es una comunidad real captada por un acto del intelecto. Por ello la metafísica es en sí misma una ciencia de lo real», ${ }^{43}$ aunque no estudia propiamente la realidad, sino sólo la copia o imagen de la esencia común de lo real reflejada en el intelecto.

El triple estado de la esencia, del que hablara Avicena, es recogido por Escoto con unas modificaciones importantes: primera, puede aplicarse también al ser, y segunda que la existencia no se añade a la esencia como el acto a la potencia, sino como la última determinación, aquella que la hace ser completa y concreta. Y en Dios, que es la esencia infinita, no hace falta ninguna determinación última, pues su esencia es infinita; es decir, la pureza formal divina es tal que Dios es la essentia tantum infinita. La existencia fáctica -la efectividad- no sólo no añadiría nada a Dios, sino que lo rebajaría, puesto que la «necesidad» es una «modalidad» superior: Dios no existe de hecho sino que existe necesariamente. ${ }^{44}$

Se comprende ahora por qué Escoto necesita distinguir entre conocimiento confuso y distinto, aplicado a las esencias. Recordemos lo que ya hemos citado: «para que un concepto sea conocido distintamente, es preciso que sea conocido todo lo incluido en la noción de su esencia». En el caso de Dios, el asunto es más complicado aún, pues Dios es simple y, al mismo tiempo, contiene en sí todas las perfecciones, las cuales, según Escoto, se distinguen con una distinción formal. Eso es lo que le llevó a considerar que el mejor modo

43 Gilson, E., 2007, 116. Escoto explica que «[la essentia tantum] no es de por sí única con una unidad numérica, ni múltiple con una multiplicidad opuesta a esta unidad; no es universal en acto, a la manera como el universal está en el entendimiento; ni es en sí particular. Aunque no exista nunca realmente sin alguna de estas determinaciones, no es, sin embargo, ninguna de ellas, sino que las precede naturalmente a todas; y por esta prioridad suya natural es el quod quid est [la sustancia en sentido aristotélico], que es por sí objeto del entendimiento y por sí es considerada por el metafísico y expresada por la definición». Duns Escoto, 1300, II, d. 3, q. 1, n. 7.

44 «Si el infinito es Dios qua Dios, si la esencia divina precede a las Personas divinas, que también son creadas y producidas, son productos, entonces el infinito conduce a algo así como a los tres estados de la esencia en Avicena. La esencia considerada como tal; no en la inteligencia, en cuyo caso es verdadera; ni in rerum naturae, en cuyo caso es ser. No, la esencia considerada simpliciter, absolute [...]. El infinito es una pureza esencial, completamente separada incluso de la noción de quidditas, porque para eso haría falta que esté in natura. Pero la esencia divina está por encima. La esencia separada, sin ninguna restricción quidditativa [...]. Lo empírico se puede suponer, lo infinito no. La infinitud está por encima de cualquier suposición, en el sentido medieval de la palabra». Polo, L., 2012, 46 y 48. 
de concebir a Dios es como «infinito», pues «cuando digo ser infinito, no tengo un concepto de un sujeto y de un atributo formado de algún modo por accidente, sino el concepto en sí de un sujeto considerado en un grado definido de perfección: la infinitud. Ocurre como en el caso de blancura intensa, que no expresa un concepto por accidente como el de blancura visible, porque la intensidad designa más bien aquí un grado intrínseco de la blancura en sí». ${ }^{45}$ ¿Es admisible este tipo de conocimiento en el tomismo? ¿Es siquiera pensable la essentia tantum, tal como la concibe Escoto?

\section{LA EVIDENCIA EN SANTO TOMÁS.}

Aunque en algunos textos tomistas antes citados aparecía la expresión «intuición», que tradicionalmente, se ha identificado con «evidencia» (inmediata), la precisión de Verneaux según la cual el concepto requiere discurso pero acaba en una intuición, es indicativa del distinto sentido que tiene el término «intuición» en santo Tomás. Además, la abstracción es un conocimiento aspectual, pero en cualquier caso, cada operación intelectual conoce lo que conoce, y eso lo conoce bien, puesto que las operaciones inmanentes poseen el fin en presente: no hay acto sin objeto, ni objeto sin acto; y tampoco hay más acto que objeto ni más objeto que acto.

Para Escoto el conocimiento verdadero es un conocimiento distinto, claro, intuido por el intelecto; en concreto, «Duns Escoto propone la siguiente regla general para asegurarse de la existencia de todo concepto distinto: es distinto de otro todo concepto del cual es posible estar seguro sin estar seguro del otro. Aquello que no está inmediatamente incluido en la certeza que se tiene del contenido de un concepto, no pertenece a ese concepto. Añadamos que, dado que el concepto alcanza aquí directamente la esencia, aquello que no está incluido en el concepto que tenemos de un ser no pertenece a su esencia». ${ }^{46}$

Como además, salvo en Dios, la existencia de lo real es contingente, su metafísica es una metafísica de la esencia, no de la existencia. La razón es que «toda ciencia - dice Duns Escoto- 'se dirige a un objeto, pero no considerado precisamente en tanto que existente'. Como dirán más tarde sus discípulos, ésta 'prescinde' de la existencia. En otras palabras, 'la existencia misma, aunque es una noción [ratio] cognoscible en el objeto o aparte del objeto, no es sin embargo necesariamente requerida como conveniente actualmente al objeto

45 Duns Escoto, J., 1300, I, d. 3, q. 2, a. 4, n. 17.

46 Gilson, E., 2007, 100. Es fácil ver la correspondencia de este texto con la primera regla del método de Descartes, y también con la regla de evidencia. 
en tanto que es objeto cognoscible': más brevemente aún: 'existentia non est per se ratio obiecti, ut scibile est'» ${ }^{47}$

Sin embargo, Escoto está convencido de estar estudiando esencias «reales», porque si el objeto de estudio es la esencia tantum, dicha esencia es la auténtica esencia real en cuanto puede considerarla la inteligencia, al margen del conocimiento sensible y al margen, también, de la lógica, que la considera como universal: «Metaphysica quae est de quidditatibus, dice Escoto. Su universo es el de las esencias [...]. Sólo es necesario no apresurarse en concluir que, para Duns Escoto, sus objetos sean sólo seres de razón. Si bien es correcta en otras filosofías, esta conclusión no lo sería en la suya, porque la 'quididad' considerada en tanto que tal no es ahí necesariamente conocida en tanto que incluida en una experiencia sensible, ni como un simple universal lógico cuya generalidad se reduce a su predicabilidad». ${ }^{48} \mathrm{La}$ esencia tantum «está en las cosas, y el intelecto la encuentra ahí, no la produce». ${ }^{49}$

Pero al prescindir de la existencia, «lo pensado es sólo esencia (pensada). Lo pensado no es real de ningún otro modo; en cuanto es un reflejo, la realidad está fuera. Pero por ser sólo pensado, a lo pensado no le falta nada para ser pensado. Y como pensar no es una actividad, la esencia en cuanto posibilidad consiste en sí misma: supone por sí misma. Ahora bien, de aquí va a surgir una distinción. Tantum se puede entender de otro modo, a saber, como el estatuto absoluto de la esencia prescindiendo de que sea real o pensada». ${ }^{50}$

Puede decirse que con Escoto la distinción entre ideas confusas y distintas, tan importante posteriormente en Descartes y los filósofos modernos, cobra una importancia capital. Escoto busca conceptos distintos; sólo después, a partir de esos conceptos, podrán formularse juicios evidentes. La razón es que los conceptos son «copias» de la realidad, y, al suplantar a la intencionalidad, su conocimiento claro y distinto es la única garantía de su «verdad». ${ }^{51}$

La postura de santo Tomás es muy distinta. Cada operación conoce su objeto, y si se desea conocer más, habrá que realizar nuevas operaciones, pero

47 Ibid., 117. La cita de Escoto, en Quaestiones Quodlibetales, VII, 8-9. «La existencia no pertenece a la razón del objeto en cuanto que es cognoscible»

48 Gilson, E., op. cit., 117.

49 Ibid., 118.

50 Polo, L., 1993, 51.

51 «Desde el momento en que se considera la abstracción como una consecuencia, en caso extremo, del pecado original, pro statu isto, deja ipso facto de ser considerada como la visión, no óptica sino intelectual, de la realidad, de las formas de las cosas, para convertirse en la producción, en el sentido estricto de la palabra producción, conjunta del intelecto agente y de la imagen sensible de un signo intelectual, de la species inteligible, que sustituye así a las cosas, que está o supone por ellas, que las representa». Inciarte, F., 2004, 160. 
no cabe decir que una operación ha conocido mal, o que su objeto sea confuso. ${ }^{52}$ Incluso cuando habla de distintos tipos de abstracción (lo que ha dado lugar a la teoría de los grados de abstracción), cada uno conoce un objeto distinto: los tipos o grados de abstracción no son conocimientos más o menos confusos, sino conocimiento de distintos objetos.

Además, y como consecuencia de lo dicho, Escoto termina en un «objetualismo» que impide la intencionalidad (la esencia tantum no es universal ni particular, la universalidad es obra del intelecto pasivo).

En resumen, con Escoto surge un nuevo modo de hacer filosofía: «la fórmula 'filosofía especulativa' puede usarse en el sentido siguiente: la filosofía es especulativa si (al margen de la distinción con la filosofía práctica) acepta que conocer es especular sobre la realidad; es decir, si se extrema la semejanza con el espejo, se sostiene una interpretación pasiva del conocimiento. En este sentido la diferencia entre la filosofía clásica y la filosofía moderna (desde su nacimiento en el siglo XIV) es justamente el paso de una filosofía teórica a una filosofía especulativa, o de la teoría a la especulación [...]. Comparada con ella [con la intencionalidad pura], la imagen especular es grosera, tosca, todavía demasiado 'abultada', a pesar de su carácter virtual. La intencionalidad pura ha de ser considerada 'desde' el acto: no 'hacia' el acto sino desde él; no como algo que sale al encuentro sino como una proyección, como un camino interiormente transitado. Se trata de invertir lo que el reflejo tiene de asalto partiendo del acto, formando el ante el acto de acuerdo con el acto-intelligere formando et formare intelligendo-, pues sólo así se elimina por completo la pasividad». ${ }^{53}$

\section{REFERENCIAS BIBLIOGRÁFICAS}

Abbagnano, N., 1994, Historia de la filosofía, I, 4a ed., Hora, Barcelona.

ALEJAndro, J. M. de, Gnoseología, 1969, BAC, Madrid.

Duns Escoto, Opus Oxoniense, 1300.

Gilson, E., Juan Duns Escoto. Introducción a sus posiciones fundamentales, 2007, Eunsa, Pamplona.

Inciarte, F., 2004, Tiempo, sustancia, lenguaje. Ensayos de metafísica, Eunsa, Pamplona.

$52 \ll E l$ realismo epistemológico no es el realismo metafísico. Sin necesidad de advertir el ser [...], la certeza es intrínseca al acontecer-pensar. Las cuestiones acerca de la certeza se reducen siempre al intento de asimilarla a nociones supuestas, es decir, de dilucidarla en ellas. Se trata, pues, de pseudo-problemas, ya que la positividad de la certeza es impensable». Polo, L., 1965, 93, nt. 25.

53 Polo, L., 1987, 118 y 119. 
Millán-Puelles, A., Léxico filosófico, 1984, Rialp, Madrid.

Miralbell, I., 1994, El dinamicismo voluntarista de Duns Escoto, Eunsa, Pamplona.

Polo, L., 1993, Presente y futuro del hombre, Rialp, Madrid.

—, 2012, Estudios de filosofía moderna y contemporánea, Eunsa, Pamplona.

—, Curso de teoría del conocimiento, I, 1987, 2ª ed., Eunsa, Pamplona,

—, El ser, 1965, Eunsa, Pamplona.

SAnto tomás de aquino, 1999 (2), 3ª ed. ampliada, De Veritate, en La verdad y la falsedad, (selección de textos, introducción, traducción y notas de Jesús García López), Cuadernos de Anuario Filosófico, Pamplona.

—, 1999, Comentario al libro IV de la Metafísica, Cuadernos de Anuario Filosófico, Pamplona.

—, 1967, Summa contra gentes, BAC, Madrid.

-, Summa Theologiae, 1959, BAC, Madrid.

Saranyana, J. I., 1985, Historia de la filosofía medieval, Eunsa, Pamplona, 1985.

VERNEAUX, R., Epistemología general o crítica del conocimiento, 1971, 2ª ed., Herder, Barcelona.

RAFAEL CORAZÓN GONZÁLEZ es profesor enseñanza media jubilado

Publicaciones:

La idea de ente. Universidad de Navarra, Pamplona 2014.

El pensamiento de Leonardo Polo. Rialp, Madrid 2011.

Kant y la ilustración. Rialp, Madrid 2004.

Lineas de investigación:

Grupo de investigación sobre el idealismo alemán y sus consecuencias actuales.

Correo-e:

rafcorazon@yahoo.es 
